\title{
Elektronik Çağda Yaradanımız Medya mı?
}

\section{iD Nil ÇOKLUK*}

* Dr. Öğr. Üyesi, Hatay Mustafa
Kemal Üniversitesi,
nilcokluk@gmail.com
Orcid ID: 0000-0002-2919-4000

Gönderilme/ Received 09.11.2021

Kabul Tarihi/ Accepted 16.11.2021

Yayın Tarihi/Published 17.11.2021
Eser Adı: Yaradanımız Medya

Yazar/Yazarlar: Marshall McLuhan ve Quentin Fiore

Çeviren: Ünsal Oskay

Şehir: İstanbul

Yayınevi: Nora Kitap

Tarih: Ekim 2019

Sayfa Sayısı: 156

Kaynak gösterme / To cite this article: Çokluk, N. (2021). Elektronik Çağda Yaradanımız Medya mı? The Journal of Communication and Social Studies, 1(1), 79-85. 
Nil ÇOKLUK

Is Media Our Creation in the Electronic Age?

iD Nil ÇOKLUK*

* Asst. Prof. Dr, Hatay Mustafa Kemal University,

nilcokluk@gmail.com

Orcid ID: 0000-0002-2919-4000

Title: Yaradanımız Medya

Author(s): Marshall McLuhan ve Quentin Fiore

Translator: Ünsal Oskay

City: İstanbul

Publisher: Nora Kitap

Year: Ekim 2019

Pages: 156

Gönderilme/ Received

09.11.2021

Kabul Tarihi/ Accepted

16.11.2021

Yayın Tarihi/Published

17.11.2021 


\section{Elektronik Çă̆, Toplumsal Değişme ve Birey}

Yaradanımız Medya kitabının başında Whitehead'in "Uygarlıktaki belli başlı ilerlemeler aslında hangi toplumda olmuşsa o toplumu paramparça eden süreçler olarak yaşanıyor" sözüyle bir giriş yapılmıştır. Buradan hareketle kitapta gündelik yaşamın elektronik teknolojisiyle insanın ilişki kalıplarının ve kişisel hayatının her yönünün dönüşümler geçirdiğine vurgu yapılmıştır. Bu dönüşümlerin bireyin yaşamını yeniden biçimlendirilip yeniden inşa ettiği üzerinde durulmaktadır. Kitap, temelde teknolojik yeniliklerin yaşamın her alanına hakim olmasını eleştirel bir şekilde ele almaktadır. Insan hayatının her alanına sirayet eden teknolojinin gündelik yaşamı ve pratikleri değiştirme biçimi kitapta şu şekilde ifade edilmektedir: "Her şey değişmekte siz, aileniz, komşularınız, eğitiminiz, işiniz, devletiniz ya da yönetiminiz 'öteki’ dediklerinizle toplumsal ilişkileriniz. Evet bütün bunlar dramatik bir değişim geçiriyor" (McLuhan ve Fiore, 2019, s. 8). Bu durum teknolojik yeniliklerin yarattığı etkinin toplumsal, kültürel, ekonomik ve teknolojik dönüşümüne vurgu yapmaktadır. $\mathrm{Bu}$ fikri Postman'nın (2006, s. 66), "tüm kültürel yaşam formlarının tekniğin ve teknolojinin egemenliğine boyun eğmesi” olarak tanımladığı teknopoli de görmek mümkündür. Teknopolinin ortaya çıkışyla din, aile, sanat, politika, tarih, gerçeklik ve zeka kavramlarının anlamı değişime uğramıştır. Böylece tanımlar teknokrasinin yeni gereksinimlerine uygun hale gelmiştir (Postman, 2006, s. 62). Postman'a (2006, s. 19) göre teknoloji “özgürlük, gerçek zeka, olgu, bilgelik, hafıza, tarih" gibi kelimeleri yeniden tanımlayarak sürekli bireylere aktarmaktadır. Bu durum, yeni teknolojilerin dünyayı algılayış biçimlerini belirlediğini ve düşünce alışkanlıklarını etkilediğini ortaya koymaktadır.

Bugün elektrik devresinin ve elektriksel donanımın herkesi herkesle bağlantılı kıldığı enformasyonun anında herkese ulaştığı bir dünyada yaşanmaktadır. Yeni enformasyonun çok hızlı bir şekilde bireylere ulaşması önceki gelenleri eskimiş ve geçersiz kılmaktadır. Elektriksel biçimlenme içindeki dünyada bireyler veri sınıflandırma alışkanlığını bırakıp, kalıp olarak tanıma-bilme tarzını benimsemek durumundadır. Çok hızlı bir şekilde işleyen iletişim dünyasında insan eylemlerinin bütün etmenleri karşılıklı ve aktif bir etkileşim, birlikte oluşum ve değişim içindedir (McLuhan ve Fiore, 2019, s.63). Bu durum Christian Fuchs'un (2012, s.72) belirttiği gibi güç yapılarının toplumsal ilişkileri şekillendirmesine neden olmaktadır.

Elektronik çă̆ ile birlikte gelen yeniliklerin yaşamın her alanına farklıklar getirip yaşamı yeniden yarattığını açıkça ortaya koymaktadır. Yaradanımız Medya (McLuhan ve Fiore, 2019, s. 8) kitabında kitle iletişim araçlarının ne'yini, nasıl'ını bilmeden yaşanan sosyal ve kültürel dönüşümleri anlamanın olanaksız olduğu vurgulanmaktadır. Bu doğrultuda kitle iletişim araçlarının yarattığı dönüşüm ve değişimi anlamak için bu araçların doğasını ve yarattığı güç ilişkilerini iyi anlayıp çözümlemek gerektiği söylenebilir. Çünkü bu araçlar toplumsal yapı ve yerleşik iletişim kalıpları ile ilgili yeni yapıların ortaya çıkmasına neden olmaktadır.

McLuhan ve Fiore yaşanan değişimlerin insan psikolojisi üzerinde yarattığı etkiye vurgu yapmaktadır. Teknolojik ve kültürel geçiş dönemlerinde insanların içini çok ciddi bir yitip gitme ve umutsuzluk duygusu sardığını belirtmektedir. 
İnsanlığın içine sürüklendiği Endişe Çağı'nın nedeni bugünün gerektirdiği işleri geçmişin araç- gereçleriyle dünün anlamlandırma ve kavramalarıyla yapmak için çabalayıp durmaktır (McLuhan ve Fiore, 2019, s. 8). Yaşanan değişim ve dönüşümün gerektirdiği düşünce kalıplarının geliştirilmesi bireylerin psikolojik, düşünsel ve zihinsel olarak yeni toplumsal yapıya uyumunu zorlaştırmakta buhranlı bir toplumsal yapının ortaya çıkmasına neden olmaktadır.

Yaşanan teknolojik gelişmelerin anlaşılması postmodern insanı anlamak açısından büyük önem taşımaktadır. Elektronik çağla birlikte teknolojik gelişmelerin hayatın her alanını sarması nedeniyle bu teknolojiler bireylerin psikolojik ve sosyal gelişiminde önemli bir rol oynamaktadır. Yaradanımız Medya kitabında bu durum şu cümleler ile anlatılmaktadır: "Elektronik medyanın yarattığı dünya çapındaki enformasyon yumağı günümüzde ana-babaların çocukların yetiştirilmesinde yapabileceğinden çok daha fazlasını yapıyor. İnsan karakterlerinin biçimlendirilmesinde iyi niyetli, candan ama pek de bu işte etkin olmayan iki uzmandan çok daha önemli yer tutuyor" (McLuhan ve Fiore, 2019, s. 14). Kitapta elektronik medyanın bireyin oluşumu üzerinde fazlasıyla belirlenimci bir yaklaşımla ele alındığı belirtilebilir. Ancak elektronik medya bireylerin karakteri üzerinde etkili olsa da tek başına belirleyici değildir.

\section{Elektronik Çağ'ın Getirdikleri ve Götürdükleri}

Kitle iletişim teknolojileri kişisel hayatı "siyasal, ekonomik, estetik, psikolojik, ahlaki ve etik" yaşam alanlarını öyle etkilemektedir ki bu araçların ilişmediği, dokunamadığı, değiştiremediği hiçbir yan kalmamış medya benlikleri tümüyle teslim almıştır. "Yaradanımız medya şimdi”. Kültürel ve sosyal değişimi anlamak için medyanın içinde bulunulan ortamı nasıl ve ne yolla oluşturduğunu irdelemeden anlamak mümkün değildir (McLuhan ve Fiore, 2019, s. 26). Elektronik enformasyon ortamında her kesimin göz önüne alınarak azınlık topluluklarının göz ardı edilemeyeceği bir ortamdan bahsedileceğini ifade eden kitapta, yeni yaşam ortamının kenarda kalmayıp olan bitene katılmayı, etrafla ilgilenmeyi zorunlu kıldığı belirtilmektedir. Elektronik çağda herkes birbirinden sorumlu bir hale gelmiştir (McLuhan ve Fiore, 2019, s. 24).

Elektronik çağla birlikte zaman ve uzam ortadan kalkmıştır. Herkes her şeyden ve herkesten her an haberdar olabilmektedir. Yeni bir diyalog biçimi ortaya çıkaran elektrik devreleri psikolojik, sosyal, ekonomik ve siyasal olarak yeni fikirleri benimsemeyenlerin sonunu getiren kökten bir değişimi ifade etmektedir. Artık mahalle kasaba, devlet, ulus gibi yapıların bir geçerliliğinin kalmadığı bir çağdayız (McLuhan ve Fiore, 2019, s. 16). Elektronik çağın en önemli getirisinin her şeyin aynı andalığı olduğunu belirten kitapta zaman durmakta ve uzam yok olmaktadır. Yani global bir köyde yaşanmaktadır. Her şeyin anda olduğu ve yaşandığı işitsel bir uzama geri dönüldüğünün belirtildiği kitapta okuryazarlıkla birlikte yitirilen kabile hissinin yeniden yaşandiğı belirtilmiştir. Elektriğin hızı sayesinde bekleyip görmeye gerek kalmazken geçmişte bu durum böyle değildir (McLuhan ve Fiore, 2019, s. 63). Elektronik çağla birlikte dünya küresel bir köye dönüşmüş ve iletişim hız kazanmıştır.

Demiryolunun toplumu ve bireyi dönüştürmesini analiz eden kitapta demiryolunun gelişiminin Amerikan Rüyası'nı gerçekleştirip kentleşmiş bir toplum ve aile yapısını ortaya çıkararak bunları tamamen değiştirdiği üzerinde 
durulmuştur. Bu durum çalışma ve iş yaşamını da değiştirmiş, işteki yönetim biçimini yeniden biçimlendirmiştir. Geleceğin elektrik donanımlı kenti, demiryolunun yarattığı devasa büyüklükte bir araya gelmiş yoğun yerleşimler şeklinde olmayacak bu kent enformasyon megapolisi olacaktır (McLuhan ve Fiore, 2019, s. 72). Bu durum enformasyon ve bilginin egemen olacağ bir toplumsal yapıyı ifade etmektedir. Günümüzde gündelik yaşamın her alanında kullanılan elektronik teknolojiler düşünüldügünde enformasyon ve bilginin öne çıktığı kentsel bir yaşamdan bahsetmek mümkündür.

Elektronik devrelerin gelişmesiyle birlikte insan gücüne duyulan ihtiyacın azalacağına vurgu yapılan kitapta "Gün gelecek bu elektronik devreler senin yaptığın işi de öğrenip yapabilecek hale gelince o zaman sen ne yapacaksın?" (McLuhan ve Fiore, 2019, s. 20) sorusu sorulmaktadir. İnsan bilincinin uzantılarının elektronik araçlar yoluyla kendilerini bir bütün olarak dünyaya yansıttığını anlatan Global Köy adlı kitapta insan türünün robotsu bir geleceğe doğru evirildiğinden bahsedilmektedir. Mcluhan ve Powers bu kitapta insan doğasının mahremiyetin ortadan kalkmasina yol açacak enformasyon sistemlerinde dönüştürüldüğünden bahsetmektedir (McLuhan ve Powers, 2001, s. 10). Teknolojideki ilerlemeyle 'insan kendi makinesinin bir yaratığg' haline gelmektedir. Harari’nin de üzerinde durduğu gibi teknolojik devrimle birlikte kısa süre içerisinde milyarlarca insan iş dünyasının dışında kalarak mevcut hiçbir ideolojinin nasıl başa çıkacağını bilmediği ani toplumsal ve siyasi değişimler yaratacak kitlelerin ortaya çıkması söz konusu olabilir (Harari, 2020, s. 33). Harari'ye göre (2020) kitlesel işsizlik tehlikesinden ziyade endişelenilmesi gereken önemli bir konu liberal anlatıya olan inancı bile ortadan kaldıracak ve dijital diktatörlüklerin ortaya çıkmasına olanak sunacak şekilde otoritenin insanlardan algoritmalara geçmesidir. İnsanlık, yeni meslekler ortaya çıksa da işlevsiz bir kitlenin belirmesine tanıklık edebilir. Yapay zekanın gelişimiyle birlikte insan gücüne duyulacak ihtiyacın azalacağı yönündeki tartışma elektronik teknolojilerin yaratacağı dönüşümleri anlatan kitapta da yer almaktadır.

Teknolojinin yarattığı kitleselliğin vurgulandığı kitapta, matbaa teknolojisinin kamuoyu yarattığını söyleyen McLuhan ve Fiore elektrik teknolojisinin bir kitle yarattığını öne sürmüştür (McLuhan ve Fiore, 2019, s. 68). $\mathrm{Bu}$ durum iletişimde hız ve kolaylık sağlayan kitle iletişim teknolojilerinin kapitalist sistemin bir yaratısı olan kitle endüstrisi ürünlerinin üretimine ve dağıtımına imkan sunması nedeniyle teknolojiye eleştirel bir şekilde bakılmasına neden olmuştur. Yaradanımız Medya kitabında McLuhan ve Fiore (2019, s. 50) matbaanın gelişimine de vurgu yaparak insanın kendini aydınlattığ gibi düzen için yıkıcı şeyleri de ele geçirip okumaya başladığı üzerinde durmuştur. Bu durum kitle iletişim araçlarının toplum ve birey üzerindeki hem yapıcı hem yıkıcı etkisini ortaya koymaktadır.

Bugünün dünyasında internet teknolojisinin gelişip yayginlaşmasıyla kitle iletişim teknolojileri siyasal yapıyı düzenlemek, değiştirmek için de kullanılabilmektedir. Siyasal yaşamdaki dönüşüm üzerine önemli analizler sunan Yaradanımız Medya'da siyasetin hala "bugünün sorunlarına dünün yanıtları ile cevap vermekte ısrar ettiğine" vurgu yapılmaktadır. Tam olarak fark edilmeyen yol ve yöntemlerle yeni bir siyaset biçiminin oluştuğu üzerinde durulan 
kitapta oturma odalarının seçim sandıklarına dönüştüğü üzerinde durulmaktadır. Artık "özgürlük yürüyüşlerine savaşa, devrimlere, çevre kirliliğine, başka birçok olaya" (McLuhan ve Fiore, 2019, s. 22) televizyon aracılığıyla katılım söz konusudur. Elektronik enformasyon medyası herkesi bir araya getirmekte, herkesi konunun içine almaktadır. Ayrıksı kalabilmek ayrı bir çevreye girebilmek artık mümkün değildir (McLuhan ve Fiore, 2019, s. 52). Sosyal medyanın yaygınlaşmasıyla birlikte bu fikrin daha da önem kazandığını söylemek mümkündür. Artık tüm toplumsal ve siyasal konulara sosyal medya aracılığıyla katılım söz konusu olabilmektedir. Ancak bu durumun özellikle demokrasi ve özgürlük açısından gerçek ve sanal katılım tartışmalarını artırdığını söylemek mümkündür.

Okuryazarlık üzerine analizlerin sunulduğu kitapta Sokrates'in Phaidros'a söylediği şu cümleler yer almaktadır (McLuhan ve Fiore, 2019, s. 113):
"Alfabenin bulunması öğrencilerin zihninde ve ruhunda unutkanlığa neden olacaktır: Çünkü belleğini ve anılarını kullanamayacak kendi dışındaki yazılı karakterlere güvenecek kendisini hatırlamayacaktır. Siz öğrencilere gerçek olanı değil, yalnızca gerçeğin benzerini verebiliyorsunuz; birçok şeyin kahramanları olacaklar, ama hiçbir şeyi bilmeyecekler; allame gibi görünecekler, ama çoğu hiçbir bilgiye sahip olmayacak."

$\mathrm{Bu}$ durum elektronik çağla birlikte gelen teknolojiler açısından önemlidir. Teknolojinin insan hayatını çok fazla kolaylaştırmış olması nedeniyle belleğe yüklenen bilgi azalmıştır. Elektronik çağın sunduğu teknolojik olanaklar sayesinde bilgiye her an ve her yerde erişebilmek, bilginin kayıtlanması zihni tembelleştirmiştir. Bireyler tüm bilgileri telefon, bilgisayar gibi teknolojik aletlerine kayıtlayıp hızlıca erişebilmektedir bu durum belleğe duyulan ihtiyacı azaltmıştır. Ong (2014), Platon'nun Phaidros diyaloğuna atıfta bulunarak "Sözlü iletişim insanları birleştirir: Yazı ve okuma ise kişinin tek başına yaptığı ve kendi iç dünyasına döndüğü eylemlerdir.” demektedir. Platon'un yazı bir nesne, imal edilmiş bir üründür fikrine benzer şekilde bu durumun bilgisayar için de geçerli olduğu üzerinde durur. Yazı zihni zayıflatmaktadır. Phaidros'ta öne sürülen temel fikir yazının doğal konuşma ve düşünmede olduğu gibi gerçek insanlar arasında bir söz alışverişi yaratamamasıdır. Yazı edilgendir ve kendi gerçekdışı yapay dünyasına kapalıdır. Ong bu durumun bilgisayar ve matbaa için de geçerli olduğunu belirtmektedir (Ong, 2014, s. 98-99). Bu teknolojiler insanı doğasından uzaklaştırarak zihni zayıflatmaktadır. Benzer bir fikri Neil Postman'nın Teknopoli adlı çalışmasında görmek mümkündür. Postman yazıyı bulan Theuth ve kral Thamus arasındaki şu diyalog ile bunu açıklamaya çalışmaktadır (Postman, 2006, s. 14):

Theuth: "Sayın kralım bu Mısırlıların bilgeliğini ve hafızalarını geliştirecek bir başarıdır. Bilgeliğin ve hafızanın reçetesini buldum” dedi.

Thamus: "Ey mucitlerin piri buluş yapmak ayrı şey buluşunun onu kullananlara fayda mı yoksa zarar mı getireceğini kestirmek ayrı şey. .... Yazıyı kullanmaya başlayanlar hafizalarını kullanmaktan vazgeçecekler ve unutkanlaşacaklar. Bir şeyleri hatırlamak için iç kaynaklarını kullanmak 
yerine harici birtakım işaretlere bel bağlamayacaklar. Sen hafıza için değil, anımsama için bir reçete keşfettin."

Yaradanımız Medya elektronik iletişim devrimini, elektronik çağın yarattığı toplumsal ve siyasal yapıyı birey açısından analiz etmeye çalışan bir kitaptır. Kitapta temelde elektronik çağın önemli getirilerinden biri olan medyanın dünyayı tamamen yeniden şekillendirmeyi vaat ettiği ve tamamen birey üzerine çalıştığı üzerinde durulmaktadır. Temelde McLuhan'ın küresel köy fikrinin de ön plana çıkarıldığı kitapta toplumsal değişimin ana gücü olarak kitle iletişim araçları gösterilmektedir (Sandywell, 2015, s. 1408). Teknolojinin hızla gelişimi düşünüldüğünde insan ilişkileri, iletişim ve etkileşim üzerindeki rolünün önemli olduğunu vurgulamak yerindedir. Elektronik teknolojilerin zaman ve mekan gibi unsurları ortadan kaldırması, bireylere küresel bir köyde yaşama imkanı sunmaktadır. Ancak bu durumun olumlu ve olumsuz sonuçlar doğurduğu söylenebilir. Bunun yanı sıra bu teknolojilerin toplumu ve bireyi büyük ölçüde dönüştürdüğünü öne sürmek mümkün olsa da insanın doğasına dair bazı unsurların radikal değişimler geçirmediği öne sürülebilir. Bu nedenle kitapta elektronik teknolojilere yönelik sunulan belirlenimci bakış açısına eleştirel bir bakış geliştirebilmek gerekmektedir. Teknolojik gelişmeler toplumsal değişme ve birey üzerinde etkiye sahip olsa da tek başına belirleyici değildir.

\section{Kaynakça}

Fuchs, C. (2014). Sosyal medya eleştirel bir giriş. Ankara: Notabene Yayınları.

Harari, Y. N. (2020). 21. yüzyıl için 21 ders. (S. Siral, Çev.) İstanbul: Kolektif Kitap.

McLuhan, M. (2001). Global köy. (B. Ö. Düzgören, Çev.) İstanbul: Scala Yayıncılık.

McLuhan, M. (2019). Yaradanımız medya. (Ü. Oskay, Çev.) İstanbul: Nora Kitap.

Ong, W. J. (2014). Sözlü ve yazllı kültür /Sözün teknolojileşmesi. (S. P. Banon, Çev.) İstanbul: Metis Yayıncılık.

Postman, N. (2006). Teknopoli: Yeni dünya düzeni. (M. E. Yılmaz, Çev.) İstanbul: Paradigma Yayınları.

Sandywell, B. (2015) The medium is the massage, Information, Communication \& Society, 18:12, 1408-1412, DOI:10.1080/1369118X.2013.868021 